\title{
PDGF-Mediated Chemoattraction of Hepatic Stellate Cells by Bile Duct Segments in Cholestatic Liver Injury
}

\author{
Nils Kinnman, Rolf Hultcrantz, Véronique Barbu, Colette Rey, Dominique Wendum, \\ Raoul Poupon, and Chantal Housset
}

Institut National de la Santé et de la Recherche Médicale U402 (NK, VB, CR, RP, CH), Faculté de Médecine Saint-Antoine, and Service d'Hépato-Gastroentérologie (NK, RP, CH), Service d'Anatomie Pathologique (DW), Hôpital Saint-Antoine, Paris, France; and Department of Gastroenterology and Hepatology (NK, RH), Karolinska Institute, Karolinska Hospital, Stockholm, Sweden

\begin{abstract}
SUMMARY: The accumulation of myofibroblasts and fibrosis around proliferating bile ducts in cholestatic liver disease has been attributed to the proliferation and phenotypic modulation of portal fibroblasts, whereas the contribution of hepatic stellate cells remains uncertain. There is increasing evidence to indicate that bile ducts may stimulate chemoattraction of hepatic stellate cells (HSC). In the present study, we undertook dynamic tests to examine such a possibility and to investigate the role of two potential mediators: platelet-derived growth factor-BB (PDGF-BB) and endothelin-1. Cholestasis was induced by bile duct ligation in rats. HSC were isolated from normal rats and culture activated into myofibroblasts expressing PDGF- $\beta$ receptors. Migration of myofibroblastic HSC was investigated in a Transwell chemotaxis filter assay. As compared with basal conditions, PDGF-BB (100 $\mu \mathrm{g} / \mathrm{l})$ and endothelin-1 $\left(10^{-8} \mathrm{M}\right)$ induced a 3-fold and 1.7-fold increase in HSC migration, respectively. Bile duct segments isolated from cholestatic rats triggered a 3 -fold increase in migration. This stimulation was significantly more potent than that observed in the presence of normal bile ducts. It was inhibited by neutralizing anti-PDGF antibodies and by STI571 PDGF receptor tyrosine kinase inhibitor, by $60 \%$ and $85 \%$, respectively, whereas Bosentan, an endothelin receptor antagonist, had no significant inhibiting effect. In bile duct segments from cholestatic rats PDGF-B chain mRNA was detected at higher levels than in controls, whereas PDGF-BB was immunolocalized in bile duct epithelial cells. The results indicate that chemotaxis of HSC towards bile duct structures may contribute to the development of periductular fibrosis in cholestatic disorders, and that PDGF-BB is the major mediator in this process. In addition, anti-liver fibrogenic properties of STI571 are suggested by potent inhibition of myofibroblastic HSC function. (Lab Invest 2000, 80:697-707).
\end{abstract}

$B$ iliary-type liver fibrosis is a complication of cholestatic liver diseases that leads to cirrhosis and portal hypertension. Fibrogenesis in the setting of cholestasic liver injury is closely associated with an increase in bile ductular structures referred to as ductular reaction. In the so-called "typical" ductular reaction (Desmet et al, 1995) newly formed bile ducts resulting from proliferation of preexisting bile duct epithelial cells, are surrounded by smooth muscle $\alpha$-actin ( $\alpha$-SMA)-positive myofibroblasts and by fibrosis. Accumulation of periductular myofibroblasts has been attributed to the proliferation and phenotypic modulation of portal fibroblasts (Tang et al, 1994; Tuchweber et al, 1996), whereas the contribution of

\section{Received January 21, 2000.}

This work was supported by the Institut National de la Santé et de la Recherche Médicale, France, and the Swedish Medical Research Council (project 9127). NK was supported by grants from the Swedish Society of Medicine, the Swedish Institute, the Swedish Society of Medical Research, the Jublin Foundation and the Karolinska Institute.

Address reprint requests to: Dr. C. Housset, INSERM Unité 402, Faculté de Médecine Saint Antoine, 27, rue de Chaligny, 75571 Paris cedex 12, France. Fax: 3314001 14 99; E-mail: chantal.housset@stantoine.inserm. fr hepatic stellate cells (HSC), generally regarded as the major source of extracellular matrix in liver fibrogenesis (Friedman, 1993), remains uncertain. HSC are normally located in the perisinusoidal space as quiescent vitamin A-storing cells secreting low amounts of extracellular matrix. Following liver injury, increased synthesis of extracellular matrix constituents occurs in combination with other phenotypic changes (also called activation) of HSC into myofibroblast-like cells. It has been demonstrated by the analysis of freshly isolated HSC, that a number of these phenotypic changes, including increased expression of extracellular matrix constituents, expression of $\alpha$-SMA and of platelet-derived growth factor receptor $\beta$-subunit (PDGFR- $\beta$ ), are induced by biliary obstruction (Maher and McGuire, 1990; Rockey and Chung, 1996; Wong et al, 1994). In addition, in situ analyses have shown that the number of desmin- and $\alpha$-SMA-positive HSC increases in the periportal areas following biliary obstruction (Grinko et al, 1995; Hines et al, 1993), raising the possibility that HSC may be recruited within the ductular reaction as a result of migration. The anatomical connection between the space of Disse and the portal interstitial space evidenced by electron microscopy studies of human and rat liver 

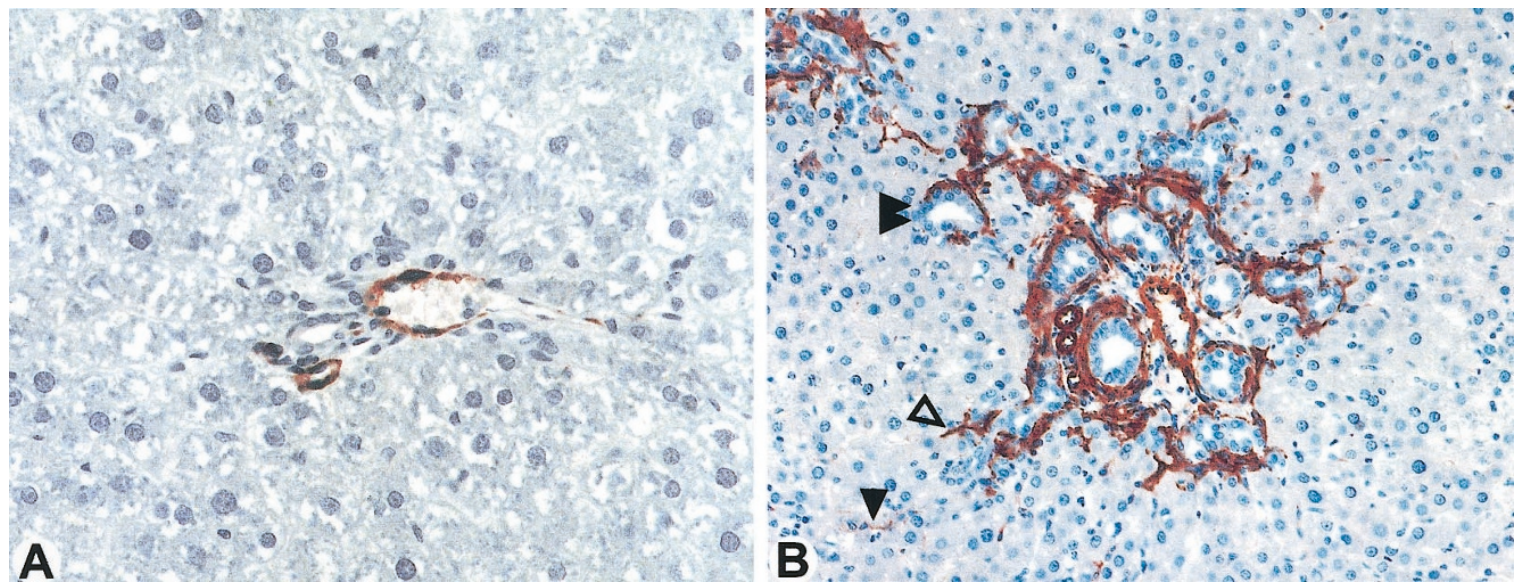

\section{Figure 1.}

Localization of myofibroblastic cells in ductular reaction. Detection of smooth muscle $\alpha$-actin ( $\alpha$-SMA) by a three-step immunoperoxidase method in the portal zone of A, normal, and B, bile duct-ligated rat liver. Color reaction was developed with 3-amino-9-ethylcarbazole, and tissue sections were counterstained with Mayer's hematoxylin. A, In normal rat liver $\alpha$-SMA immunoreactivity is confined to portal vessel walls. B, After bile duct ligation, $\alpha$-SMA-positive cells accumulate around proliferative bile ducts. In the periphery of ductular reaction, newly formed bile ducts may be incompletely encircled by $\alpha$-SMA-positive cells (double arrowhead), and sinusoidal $\alpha$-SMA-reactive cells are visible (closed arrowhead), that may be in close apposition to ductular formation (open arrowhead). Original magnifications: A, $\times 400 ; B, \times 200$

(Hardonk and Atmosoerodjo-Briggs, 1992) is consistent with such a possibility.

Based on recent in vitro experiments, it has been established that human and rat HSC are able to migrate according to concentration gradients of chemotactic factors (lkeda et al, 1999; Marra et al, 1997, 1999). The best characterized chemotactic factor for HSC identified thus far is the platelet-derived growth factor-BB (PDGF-BB) (Carloni et al, 1997; Ikeda et al, 1999; Marra et al, 1997). PDGF-BB is also known as the most potent mitogen for HSC, and is overexpressed during active hepatic fibrogenesis (Friedman and Arthur, 1989; Pinzani et al, 1989, 1996b). Among factors that induce chemotaxis of other types of mesenchymal cells, the vasoactive peptide endothelin-1 (ET-1) (Peacock et al, 1992) is of particular interest in the setting of liver fibrogenesis, because the local production of ET-1 is dramatically increased in liver injury (Pinzani et al, 1996a; Rockey et al, 1998). Moreover, ET receptors on HSC far outnumber those on other liver cell populations, pointing to $\mathrm{HSC}$ as a major target for ET-1 within the liver. We and others previously showed that ET-1 is a powerful agonist of HSC contraction, suggesting that it may also act on cell motility (Housset et al, 1993b; Pinzani et al, 1996a). Both PDGF-BB and ET-1 have been recently identified within bile duct epithelial cells, by in situ analyses (Grappone et al, 1999; Pinzani et al, 1996a). In the present study we undertook functional tests to examine the possibility that HSC may migrate towards bile duct structures within the ductular reaction, and to determine the role of PDGF-BB and of ET-1 in mediating this process.

\section{Results}

\section{Bile Duct Ligation-Induced Ductular Reaction}

Bile duct ligation (BDL) provoked ductular reaction and liver fibrogenesis, as described (Kountouras et al,
1984). The number of bile duct sections gradually increased from day 1 to day 21 , in parallel with the accumulation of myofibroblastic cells expressing $\alpha$-SMA. Whereas in normal liver, the distribution of $\alpha$-SMA-positive cells was confined to the wall of portal vessels (Fig. 1A), and of terminal hepatic venules (data not shown), bile duct ligation was followed by an increase in the number of $\alpha$-SMA-positive cells that intimately encircled bile duct structures (Fig. 1B). In the periphery of ductular reaction, a portion of newly formed bile ducts were incompletely surrounded by $\alpha$-SMA-positive cells. In addition, $\alpha$-SMA-positive cells in periportal sinusoids were visible in the vicinity of ductular areas, consistent with the active recruitment of activated myofibroblastic HSC by ductular structures. We next investigated this potential mechanism, by dynamic tests, using myofibroblastic HSC in a chemotaxis filter assay.

\section{PDGF-BB- and ET-1-Induced Chemotaxis of Myofibroblastic HSC}

HSC were isolated from normal rats, and activated within 10 to 14 days in culture to a myofibroblastic phenotype, as ascertained by the acquisition of $\alpha$-SMA (Fig. 2A) and of PDGFR- $\beta$ expression (Fig. 2, B and $C$ ). We verified that PDGFR- $\beta$ protein reactivity was retained in HSC detached from the culture plate by trypsin- ethylenediaminetetraacetate (EDTA) (Fig. 2B). After trypsin-EDTA treatment, myofibroblastic HSC were seeded in the upper compartment of the chemotaxis filter assay, and were allowed to migrate through the filter in response to PDGF-BB gradients (Fig. 3A). After the addition of PDGF-BB $(100 \mu \mathrm{g} / \mathrm{l})$ in the lower compartment of the chemotaxis filter assay, HSC migration was increased by more than 3 -fold as compared with controls (Fig. 3B). In the presence of anti-PDGF IgG, PDGF-BB-induced migration was reduced by $78 \%$, whereas non-selective isotype- 

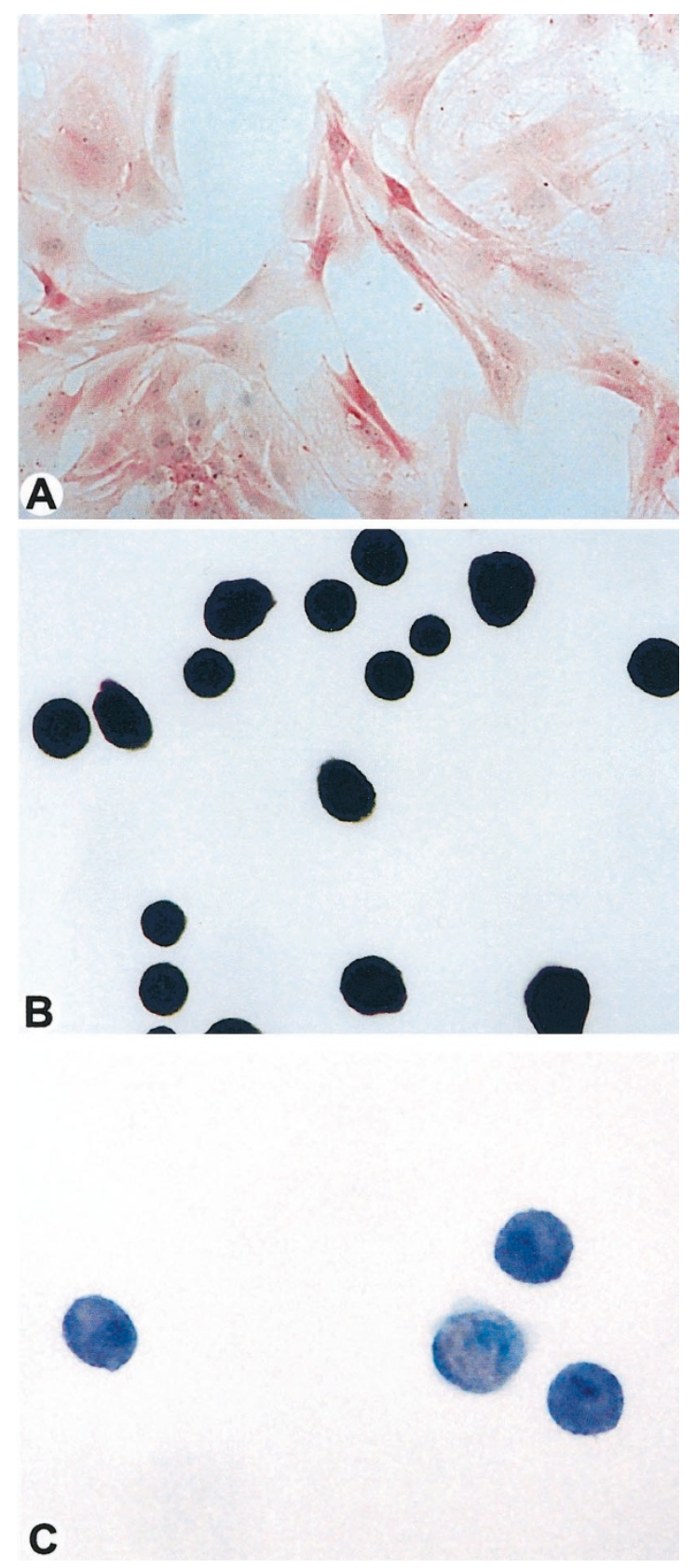

Figure 2.

Myofibroblastic phenotype of culture activated hepatic stellate cells (HSC). HSC were activated in culture and grown on Labtek slides. After fixation in acetone, $\alpha$-SMA was detected by immunocytochemistry using the alkaline phosphatase-anti-alkaline phosphatase method. The expression of plateletderived growth factor receptor $\beta$-subunit (PDGFR- $\beta$ ) on cell membranes was determined following detachment of HSC with trypsin-EDTA (ethylenediaminetetraacetate). Detached HSC, appearing as rounded cells, were allowed to adhere to positively charged glass slides and were fixed in $4 \%$ paraformaldehyde. B, PDGFR- $\beta$ was detected by the biotin-avidin immunoperoxidase method. C, Anti-PDGFR- $\beta$ monoclonal antibody was replaced by irrelevant isotype-matched immunoglobulins in the negative control. A, Color reaction was developed with Fast red, and B and $\mathrm{C}$, with diaminobenzidine. Original magnification, $\times 400$.

matched IgG had no significant inhibiting effect (Fig. $3 C)$. In addition, the chemotactic activity of PDGF-BB was abolished by STI571, an inhibitor of the PDGF receptor tyrosine kinase (Buchdunger et al, 1996; provided by Dr. Elisabeth Buchdunger, Novartis Pharma Inc., Basel, Switzerland; Fig. 3C). HSC chemotaxis also occurred in response to ET-1 gradients, although the stimulating effect of ET-1 was weaker than that of PDGF-BB. ET-1 $\left(10^{-8} \mathrm{M}\right)$ triggered a 1.7-fold increase in HSC migration (Fig. 4A), and this chemotactic activity was reduced by $90 \%$ by Bosentan $\left(10^{-5} \mathrm{M}\right)$, a mixed $\mathrm{ET}_{\mathrm{A}}-\mathrm{ET}_{\mathrm{B}}$ receptor antagonist (Clozel et al, 1994; provided by Dr. Martine Clozel, Actelion Ltd., Allschwil, Switzerland; Fig. 4B). In addition, when both ET-1 $\left(10^{-8}\right.$ M) and PDGF-BB (10 $\mu \mathrm{g} / \mathrm{l})$ were introduced in the lower chamber, their chemotactic effects were additive (Fig. $4 A$ ), suggesting that both mediators could cooperate in driving HSC chemotaxis, in vivo. Evidence that they both acted through separate receptors was further provided by the fact that STI571 had no effect on ET-1 induced chemotaxis (Fig 4B) and vice versa. In the presence of Bosentan $\left(10^{-5} \mathrm{M}\right), \mathrm{HSC}$ migration induced by PDGF-BB $(100 \mu \mathrm{g} / \mathrm{l})$ was $106 \pm 12 \%$ of that induced by PDGF-BB in the absence of Bosentan ( $n=5, \mathrm{NS})$. When ET-1 or PDGF-BB were introduced in the upper compartment instead of the lower compartment, no significant increase in the number of cells entering the filter was noted (not shown), indicating that ET-1- and PDGF-BBinduced migration was due to chemotaxis rather than chemokinesis.

\section{HSC Chemotactic Response to Bile Duct Segments}

To test the hypothesis of HSC chemoattraction in ductular reaction, bile duct segments were isolated from normal and 21-day BDL rats, and placed in the lower compartment of the Transwell chemotaxis filter assay. Freshly isolated bile duct segments appeared as ductular or rounded structures. At least $90 \%$ of the cells were identified as biliary epithelial cells based on cytochemical and immunocytochemical analyses, as described below. They were allowed to adhere and then placed in serum-free medium 24 hours before the assay. Incubations with bile duct segments from both normal and bile duct-ligated rats resulted in the chemoattraction of myofibroblastic HSC, as assessed by 1.7-fold and 3-fold increases in HSC migration, respectively (Fig. 5A). The difference was statistically significant, whereas the number of bile duct cells introduced in the lower wells did not differ between normal and BDL rats, as ascertained by cell count and DNA content (not shown). The results therefore indicated that bile duct segments from BDL rats exerted more potent chemotactic effects than bile duct segments from normal rats on myofibroblastic HSC. To next determine whether the chemotactic effect of bile duct segments from BDL rats was mediated by PDGF-BB and/or ET-1, incubations of HSC with bile duct segments from BDL rats were repeated in the presence of inhibitors (Fig. 5B). In the presence of Bosentan, the number of HSC migrating through the filter tended to decrease, but the difference with controls did not reach significance. Incubation with neutralizing anti-PDGF IgG caused a reduction of HSC migration by almost $60 \%$, and no additive inhibitory effect ensued when Bosentan was used together with 


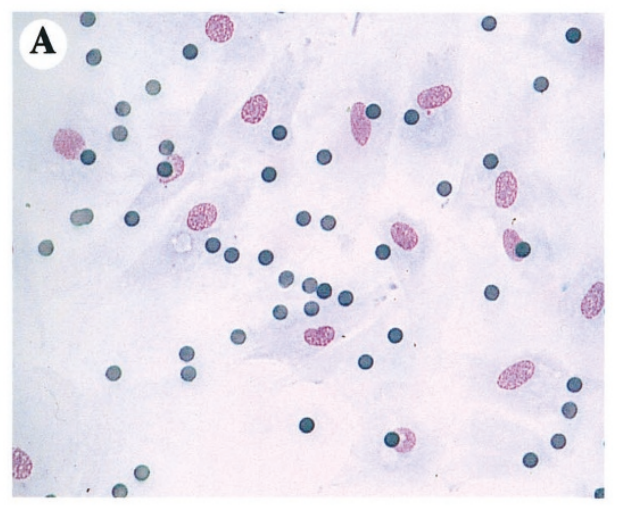

B
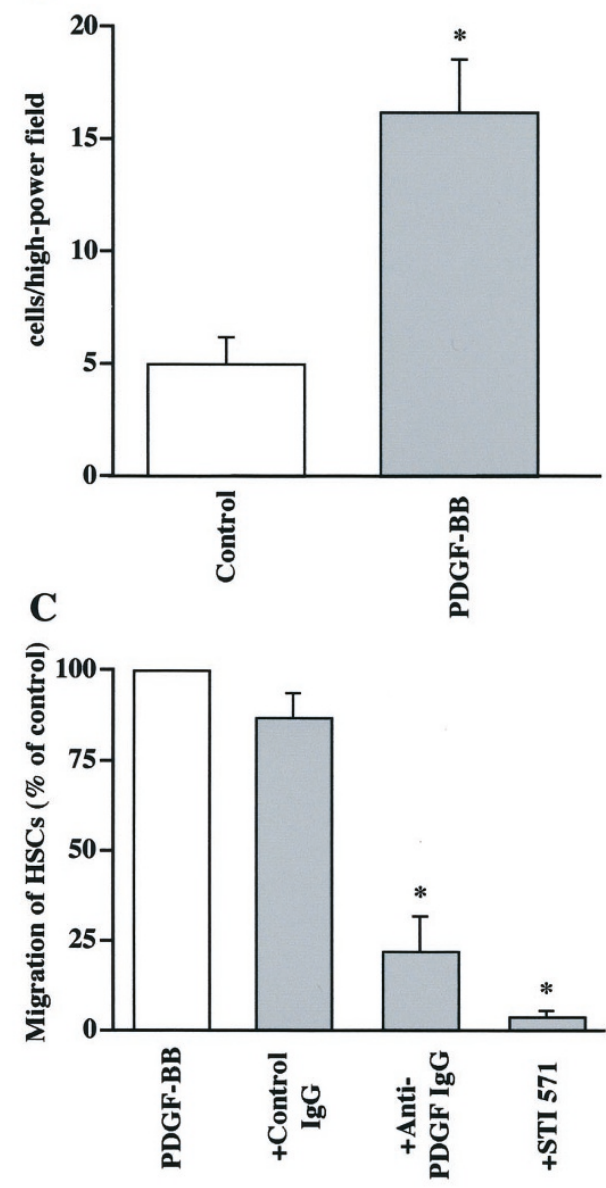

Figure 3.

Platelet-derived growth factor-BB (PDGF-BB)-induced chemotaxis of HSC. Serumstarved myofibroblastic HSC were seeded in the upper compartment of the Transwell chemotaxis filter assay. PDGF-BB (100 $\mu \mathrm{g} / \mathrm{l})$ or medium alone in controls, were added to the lower compartment, and HSC were allowed to migrate for 6 hours to the lower surface of the separating membrane. At the end of migration, the upper surface of the membrane was cleaned, and the cells adhering to the lower surface were fixed in methanol and stained with May-GrünwaldGiemsa. A, HSC that have migrated through the 8- $\mu \mathrm{m}$ pores (black dots) to the lower surface of the membrane are shown. Original magnification, $\times 400$. B and $C$, the number of HSC adhering to the lower surface were counted in 10 random high-power fields $(\times 400)$ and averaged. C, In blocking experiments, PDGF-BB (50 $\mu \mathrm{g} / \mathrm{l})$ was added to the lower compartment, with or without (in controls), neutralizing anti-PDGF IgG (50 mg/l), non-selective lgG (50 mg/l) or STI571 (10 M). Results are expressed as means \pm SEM of at least 3 separate experiments performed in duplicate. ${ }^{*} p<0.05$, in comparison with the corresponding controls.
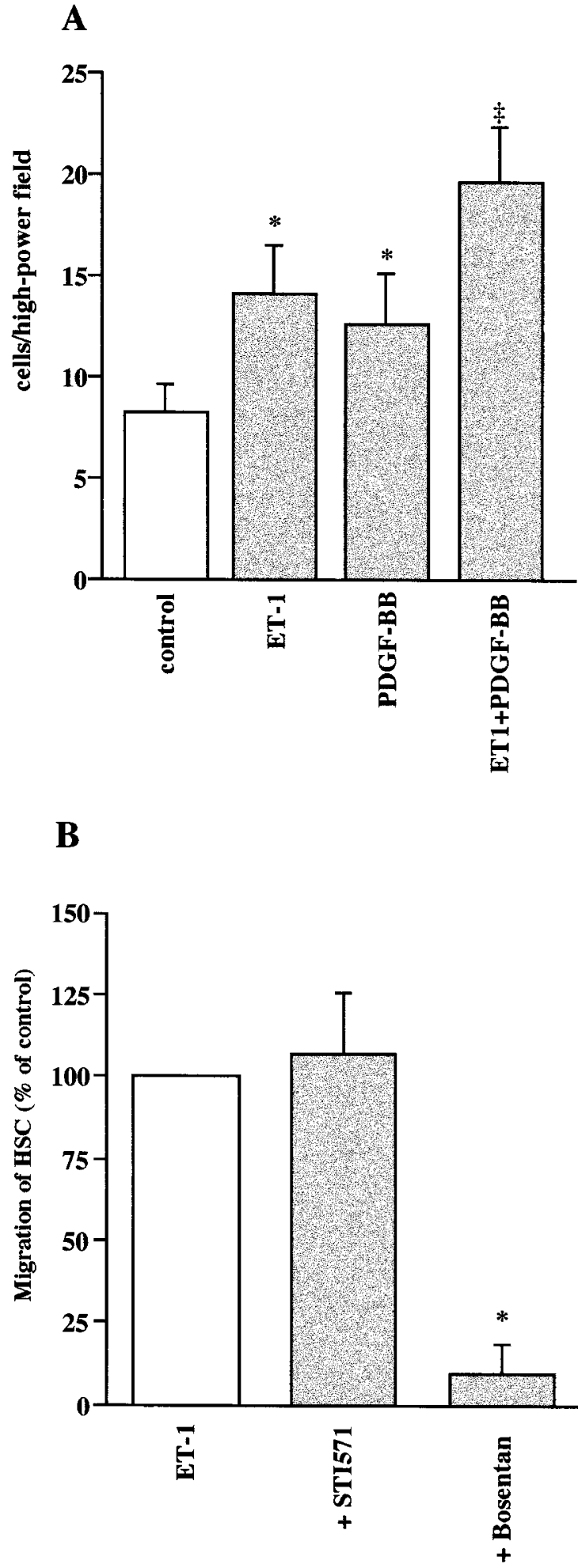

Figure 4.

The vasoactive peptide endothelin-1 (ET-1)-induced chemotaxis of HSC. Serum-starved myofibroblastic HSC were subjected to a Transwell chemotaxis filter assay, as in Figure 3. A, medium alone in controls, ET-1 $\left(10^{-8} \mathrm{M}\right)$ and/or PDGF-BB $(10 \mu \mathrm{g} / \mathrm{l})$ were added to the lower compartment. B, In blocking experiments, ET-1 (10-8 $\mathrm{M})$ was added to the lower compartment with or without (in controls), STI571 $\left(10^{-5} \mathrm{M}\right)$ or Bosentan $\left(10^{-5} \mathrm{M}\right)$. Results are expressed as means \pm SEM of at least five separate experiments performed in duplicate. ${ }^{*} p<0.05$, in comparison with the corresponding controls. ${ }^{\ddagger} p<$ 0.05 , in comparison with ET-1 and PDGF-BB alone. 

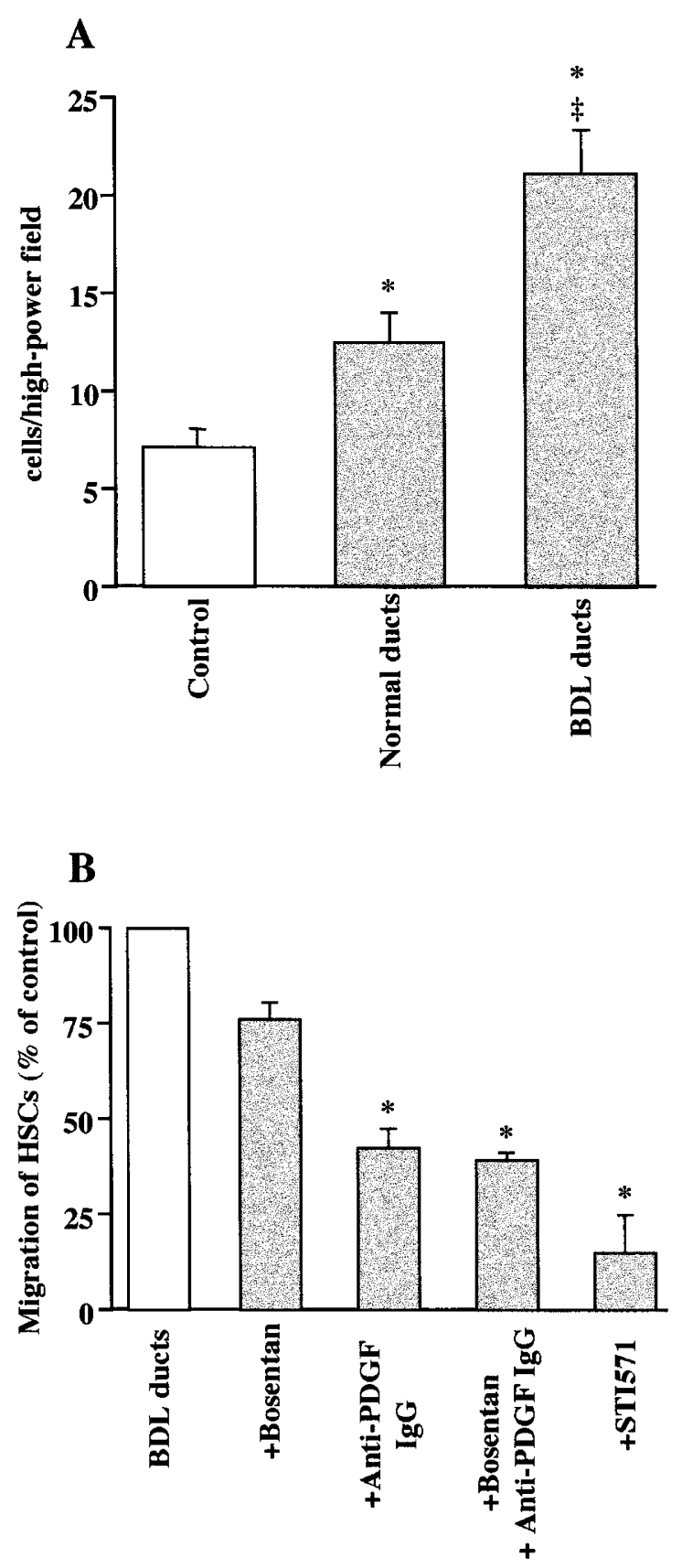

Figure 5 .

Bile duct-induced chemotaxis of HSC. Serum-starved myofibroblastic HSC were subjected to a Transwell chemotaxis filter assay, as in Figure 3. A, Medium alone in controls, freshly isolated bile duct segments from normal or 21-day bile duct-ligated rats were placed in the lower compartment. The cell number did not differ between wells as ascertained by cell count and DNA content. B, In blocking experiments, freshly isolated bile duct segments from 21-day BDL rats were placed in the lower compartment with or without (in controls), Bosentan $\left(10^{-5} \mathrm{M}\right)$ and/or neutralizing anti-PDGF $\mathrm{lgG}(50 \mathrm{mg} / \mathrm{l})$, or STI571 $\left(10^{-5} \mathrm{M}\right)$. Results are expressed as means \pm SEM of at least four separate experiments performed in duplicate. ${ }^{*} p<0.05$, in comparison with the corresponding controls. ${ }^{\ddagger} p<0.05$, in comparison with bile duct segments from normal rats.

anti-PDGF IgG, indicating that the contribution of ET-1 is minor, as compared with PDGF. Finally, HSC migration in response to bile duct segments from BDL rats, was decreased by $85 \%$ by STI571. The resulting migration activity was not significantly different from basal level, indicating that the chemotactic activity of bile ducts following biliary obstruction is to a large extent PDGF-mediated, and suggesting that PDGF production arises from bile duct segments.

\section{Expression of PDGF-BB in Bile Duct Segments}

To examine PDGF synthesis, we first undertook the detection of PDGF-B chain mRNA by reverse transcription-PCR (RT-PCR), in bile duct segments from $\mathrm{BDL}$ rats. The level of expression was evaluated in comparison with bile duct segments and hepatocytes isolated from normal rats, and with culture activated myofibroblastic HSC, by monitoring the kinetics of amplification of PDGF-B and glyceraldehyde-3-phosphate dehydrogenase (G3PDH) cDNAs during PCR. Whereas the signal for PDGF-B chain mRNA was readily detectable in bile duct segments from normal and BDL rats after 24 cycles, a weak signal became detectable in hepatocytes and myofibroblastic HSC, only after the completion of 36 cycles, providing evidence that expression of PDGF-B chain was considerably higher in bile duct segments than in hepatocytes or myofibroblastic HSC. Within the exponential phase of amplification, at 30 cycles, shown in (Fig. 6), the ratio of PDGF-B and G3PDH signals was $0.84 \pm 0.05$ (mean \pm SEM) in bile duct segments from BDL rats, as opposed to $0.56 \pm$ 0.05 in bile duct segments from normal rats $(p<0.05)$, consistent with an increase in PDGF-B chain transcripts in bile duct segments following bile duct ligation. Cytochemical and immunocytochemical analyses of freshly isolated bile duct fragments provided evidence that PDGF-BB production occurred in bile duct epithelial cells. More than $90 \%$ of the cells forming isolated bile duct segments were identified as biliary epithelial cells by cytokeratin 19 immunolabeling (Fig. 7A) and by $\gamma$-GT staining (Fig. 7B). Despite the fact that bile duct segments from normal rats displayed occasional reactivity for $\alpha$-SMA (Fig. 7C), and that this reactivity increased following bile duct ligation, the proportion of $\alpha$-SMApositive cells never exceeded $10 \%$ of total cells in isolated segments (Fig. 7D), and unlikely accounted for PDGF-B chain expression in the entire duct structures, because only a very weak signal for PDGF-B chain was

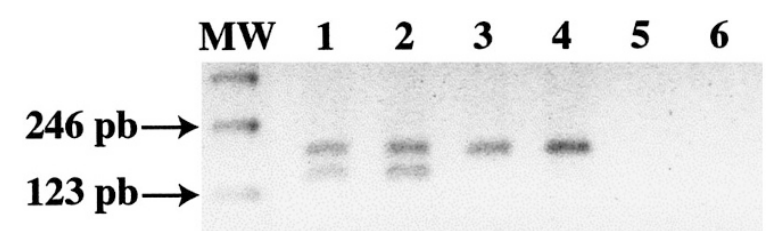

Figure 6.

Expression of PDGF-B chain mRNA in bile duct segments. Total RNA $(1 \mu \mathrm{g})$ from bile duct segments isolated from normal (lane 1) and BDL rats (lane 2), from myofibroblastic HSC (lane 3), and from hepatocytes (lane 4) were subjected to G3PDH and PDGF-B RT-PCR. 195-bp G3PDH and 149-bp PDGF-B amplified products, were withdrawn after 30 PCR cycles and separated on ethidium bromide-stained agarose gel. MW: 123-bp DNA-ladder; lanes 5 and 6: RT and PCR negative controls, respectively. The gel is representative of results obtained from at least 3 separate cell preparations. 

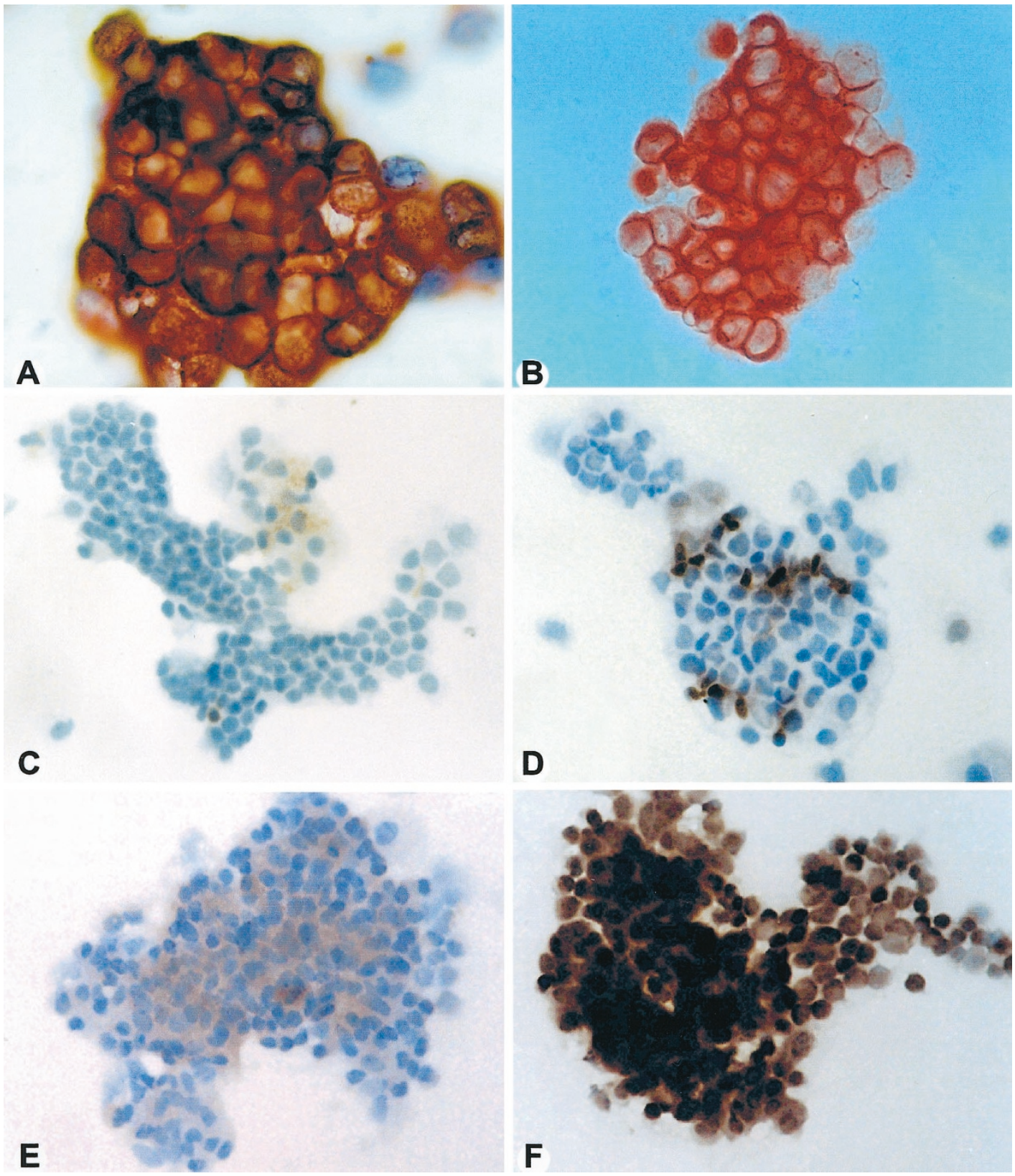

\section{Figure 7.}

Immunolocalization of PDGF-BB in bile duct segments. Identification of biliary epithelial cells in bile duct segments isolated from 21-day bile duct-ligated rats by immunolabeling of cytokeratin 19, A, using a biotin-avidin-peroxidase method, and B, $\gamma$-GT staining. C and D, Immunodetection of $\alpha$-SMA and E and F, of PDGF-BB, by a biotin-avidin-peroxidase method, $\mathrm{C}$ and $\mathrm{E}$, in bile duct segments from normal, and $\mathrm{D}$ and $\mathrm{F}, 21$-day bile duct-ligated rats. Color reaction was developed with diaminobenzidine and the preparations were counterstained with Mayer's hematoxylin. D, Less than 10\% cells immunoreactive for $\alpha$-SMA are detected in bile duct segments from BDL rats, and C, less than $1 \%$ in bile duct segment from normal rats. PDGF-BB immunolabeling of low and high intensities, is detected in bile duct segments from $E$, normal, and $F, B D L$ rats, respectively. Original magnifications, $A, \times 1000 ; B, \times 600 ; C$ to $F, \times 400$.

detected in myofibroblastic cells by RT-PCR. Moreover, in bile duct segments from 21-day BDL rats, PDGF-BB immunolabeling was much more intense than in segments from normal rats (Fig. 7, E and F), and comprised the cells identified as biliary epithelial cells.

\section{Discussion}

In keeping with an important role of HSC in liver wound healing, it has been proposed that following necrotic injury, HSC detach from the sinusoidal wall and move into post-necrotic areas. This assumption has recently been reinforced by the demonstration of HSC migratory capacities, particularly in response to PDGF-BB (Carloni et al, 1997; Ikeda et al, 1999; Marra et al, 1997, 1999). In the present study, we provide evidence that HSC may also migrate in cholestatic liver injury and accumulate within the ductular reaction as a result of PDGF-mediated chemoattraction by bile duct structures. The major findings supporting this evidence were that bile duct segments isolated from 
bile duct-ligated rats exhibited high levels of PDGF-B chain mRNA and protein, that they were very active in inducing chemotaxis of myofibroblastic HSC, and that this effect was inhibited by blocking PDGF-BB ligand or receptor activity. Activity of the receptor downstream signaling cascade was blocked by STI571, previously known as CGP 57148. STI571 is a protein-tyrosine kinase inhibitor of the 2-phenylaminopyrimidine class that shows potent and selective inhibition of PDGFmediated events, such as PDGF receptor autophosphorylation, c-fos mRNA induction, PDGF-driven cell proliferation in vitro and tumor growth in vivo (Buchdunger et al, 1996). The different isoforms of PDGF (AA, $A B, B B)$ exert their effects on target cells by binding to two structurally related but distinct protein tyrosine kinase receptors: PDGF- $\alpha$ receptor binds all three isoforms with high affinities, whereas $\beta$ receptor binds $A B$ and BB isoforms only (Hart et al, 1988; Heldin et al, 1988). The expression of PDGF- $\alpha$ receptor is constitutive in quiescent $\mathrm{HSC}$, and that of $\beta$ receptor is acquired as the cells undergo myofibroblastic phenotypic changes (Wong et al, 1994). Both receptors are thus expressed in myofibroblastic HSC and could theoretically be implicated in chemotaxis. Blocking experiments did not allow discrimination between the role of $\alpha$ and $\beta$, inasmuch as STI571 displays no specificity for either subtype. Yet, the chemotactic effect of PDGF-BB implies that PDGF- $\beta$ receptor is involved. Moreover, it was shown before that PDGF-AA is not chemotactic for human HSC, as opposed to PDBF-BB (Marra et al, 1997), and even that PDGF- $\alpha$ receptor mediates antagonism of chemotaxis in human fibroblasts (Vassbotn et al, 1992). We may therefore postulate that the chemotactic effect of bile ducts was mediated predominantly by PDGF- $\beta$ receptors in myofibroblastic HSC.

We herein also report for the first time that ET-1 acts as a chemotactic factor for HSC. We used Bosentan, a nonpeptide mixed antagonist of endothelin receptors, which competitively antagonizes the specific binding of $\mathrm{ET}-1$ on $\mathrm{ET}_{\mathrm{A}}$ and $\mathrm{ET}_{\mathrm{B}}$ receptors (Clozel et al, 1994), to evaluate the role of ET in chemotaxis induced by bile duct segments. It was previously shown that ET-1 exerts an array of biological effects on HSC and modulates liver fibrogenesis (Housset et al, 1993b; Mallat et al, 1995; Pinzani et al, 1996a; Poo et al, 1999; Rockey et al, 1998). A number of findings point to proliferative bile duct epithelial cells in addition to endothelial cells and myofibroblastic HSC, as a major source of ET-1 within the liver (Housset et al, 1993b; Pinzani et al, 1996a). Accordingly, we could document an abundance of ET-1 precursor mRNA in bile duct segments from bile duct-ligated rats (not shown). Nevertheless, we failed to show that Bosentan, either alone or in combination with anti-PDGF antibodies, has a significant effect on the chemotaxis of HSC induced by bile duct segments from BDL rats, although Bosentan was effective in blocking ET-1induced chemotaxis. Although it is not excluded that the amount of ET-1 released by bile duct segments in vitro was artificially diluted in the chemotaxis filter assay, and that the local concentration of ET-1 produced by bile ducts in vivo is sufficient to stimulate
HSC migration, our results suggest that the role of ET-1 in mediating bile duct-induced migration of HSC is minor as compared with that of PDGF-BB.

PDGF-BB expression in bile duct segments from normal rats probably accounts for the fact that, to some extent, they stimulated migration of myofibroblastic HSC, which however may not apply to normal HSC expressing no or low levels of PDGFR- $\beta$. Bile duct-induced chemoattraction of HSC is more likely to occur in cholestatic liver injury when both the expression of PDGF-BB in bile ducts and that of PDGFR- $\beta$ in HSC increase. Because bile duct segments from cholestatic rats contained a small number of $\alpha$-SMApositive cells, the question of whether these cells might contribute to PDGF-BB synthesis was raised. The low level of PDGF-B chain mRNA in myofibrobastic HSC as compared with bile ducts, and the similar patterns of PDGF-BB and of cytokeratin-19 immunolabeling, in bile duct segments from cholestatic rats, argue against such a possibility. We therefore concluded that PDGF-BB production in bile ducts arises at least to a great extent from biliary epithelial cells, in agreement with Grappone et al (1999), who performed in situ hybridization in cholestatic rat liver tissue, and RNase protection analysis of virtually pure rat cholangiocytes. The results from present and previous work showing that cholestatic liver injury is accompanied by HSC activation (Abdel-Aziz et al, 1991; Grinko et al, 1995; Hines et al, 1993; Maher and McGuire, 1990; Wong et al, 1994) and by a progressive increase in hepatic expression of PDGFR- $\beta$, (Grappone et al, 1999) are consistent with the view that HSC contribute, in addition to portal fibroblasts (Tang et al, 1994; Tuchweber et al, 1996), to the population of $\alpha$-SMApositive periductular cells in chronic obstructive cholestasis.

The possibility that in human chronic liver diseases, newly formed bile ducts are, in addition to inflammatory cells and activated HSC, a major source of PDGF, is supported by investigations of human cirrhotic liver tissue (Malizia et al, 1995; Pinzani et al, 1996b). Our study provides the first demonstration that dynamic interactions between bile duct epithelial cells and HSC may occur. This mechanism can be proposed to explain the accumulation of HSC within collagen depositions around bile ducts in the absence of marked necrosis and inflammation, as described in electronmicroscopical studies of liver tissue in cystic fibrosis liver disease (Hultcrantz et al, 1986; Lindblad et al, 1992). In this study we also demonstrate potent inhibiting effects of STI571 on HSC response to PDGF-BB in vitro, indicating that this compound could have antifibrogenic properties by blocking the effect of PDGF-BB in vivo.

\section{Materials and Methods}

\section{Reagents}

Anti- $\alpha$-SMA monoclonal antibody, bovine serum albumin (BSA), D-glucose, Dulbecco's modified Eagle medium (DMEM), DMEM and Ham's F12 (1:1) mixture 
(DMEM/Ham's F12), ethylenediaminetetraacetate (EDTA), ET-1, fast blue BB, $\gamma$-Glutamyl-4-methoxy-2-naphthylamide, Glycylglycine, N-2-hydroxyethylpiperazine-N'-2ethane sulfonic acid (Hepes), horse serum, Leibowitz L15 medium, minimum essential medium, Nycodenz, trypsin and trypsin inhibitor were purchased from Sigma (Saint-Quentin Fallavier, France). Collagenase B, deoxyribonuclease, hyaluronidase, pronase and PDGF-BB were from Boehringer Mannheim (Mannheim, Germany). Fetal calf serum, fungizone, Hanks' buffer, penicillinstreptomycin, and Superscript reverse transcriptase were obtained from GIBCO BRL (Life Technologies, CergyPontoise, France). I-glutamine was from Eurobio (Les Ulis, France), type I collagen, from Becton-Dickinson (Le Pontde-Claix, France), and Ultroser G, from Biosepra (Villeneuve-la-Garenne, France). QIAamp Blood Kit and RNAVDNA kit were from Qiagen (Courtaboeuf, France). Random hexamers and Taq DNA polymerase were from Pharmacia Biotech (Orsay, France). Anti-cytokeratin 19 monoclonal antibody, anti-PDGFR- $\beta$ and anti-PDGF-BB polyclonal antibodies were obtained from Amersham Life Science (Little Chalfont, United Kingdom), from Santa Cruz Biotechnology Inc. (Santa Cruz, California), and from Genzyme (Cambridge, Massachusetts), respectively. Rabbit anti-mouse and peroxidase conjugated anti-mouse and anti-rabbit immunoglobulins, alkaline phosphatase antialkaline phosphatase complex, Fast red and Glycergel were from Dako S.A. (Trappes, France). SP-2001 blocking kit, biotinylated anti-rabbit lgG, Vectastain ABC-HP-kit, 3-amino-9-ethylcarbazole and diaminobenzidine were from Vector Lab. (Burlingame, California).

\section{Experimental Model of Cholestatic Liver Injury}

Cholestatic liver injury was induced in male SpragueDawley rats ( $R$ Janvier, Le Genest St Isle, France) weighing 200 to $250 \mathrm{~g}$, by double ligation and sectioning of the common bile duct, as described (Kountouras et al, 1984), and sham operated rats served as controls. Histological and immunohistochemical analyses were performed on formalin-fixed paraffinembedded liver samples. Serial 4- $\mu \mathrm{m}$-thick tissue sections were stained with hematoxylin and eosin, or submitted to a three step immunoperoxidase method, for the detection of $\alpha$-SMA, as described below.

\section{Isolation of Intrahepatic Bile Duct Segments}

Intrahepatic bile duct segments were isolated from normal and bile duct-ligated rats, 21 days after BDL, using a method described by Mennone et al (1995), with modifications. In brief, the liver was perfused in situ, at a flow rate of $10 \mathrm{ml} / \mathrm{minute}$, with $0.019 \%$ EDTA in $\mathrm{Ca}^{2+}, \mathrm{Mg}^{2+}$-free Hanks' buffer for 15 minutes, and then with $0.008 \%$ collagenase $\mathrm{B}$ in $\mathrm{Ca}^{2+}, \mathrm{Mg}^{2+}$ containing Hanks' buffer, for 10 to 15 minutes. The portal tract residue was mechanically separated from parenchymal tissue, minced and incubated for 30 minutes under agitation at $37^{\circ} \mathrm{C}$, in minimum essential medium containing $0.066 \%$ collagenase $\mathrm{B}, 0.055 \%$ pronase, $0.006 \%$ deoxyribonuclease, $3 \%$ fetal calf serum, 0.1\% BSA, 10 mm Hepes, and 100,000 IU-100 $\mathrm{mg} / \mathrm{l}$ penicillin-streptomycin. The suspension was then sequentially filtered through 100- and 40- $\mu \mathrm{m}$ Nitex Swiss nylon monofilament filters (Becton-Dickinson). Fragments remaining on the filters were digested in the same solution for 30 minutes and for an additional 30 minutes in a solution of the same composition except that hyaluronidase $(0.036 \%)$ was substituted for pronase. Fragments were filtered again and those remaining on the $40-\mu \mathrm{m}$ filter were collected and washed in L15.

\section{Isolation and Culture of Hepatic Stellate Cells (HSC)}

HSC were isolated from normal rats by an established method (Friedman and Roll, 1987) with modifications. The liver was perfused in situ at a flow rate of 10 $\mathrm{ml} /$ minute, successively with L15 for 15 minutes, with $0.18 \%$ pronase in DMEM/Ham's F12 for 10 minutes, and then with $0.025 \%$ collagenase B in DMEM/Ham's $\mathrm{F} 12$, via recirculation for 20 to 25 minutes. The liver was excised and the cells were detached in DMEM/ Ham's F12 containing $0.04 \%$ pronase and $6 \mathrm{mg} / \mathrm{l}$ deoxyribonuclease, and incubated under agitation at $200 \mathrm{rpm}$ and at $37^{\circ} \mathrm{C}$, for 30 minutes. The cell suspension was filtered through gauze and washed in DMEM/Ham's F12. HSC were then separated by density gradient centrifugation through $8.2 \%$ Nycodenz, at $20.000 \mathrm{rpm}$ and at $19^{\circ} \mathrm{C}$, for 25 minutes. The purity of HSC isolates was higher than $98 \%$, as assessed by fluorescence of retinoid-containing vacuoles under ultraviolet excitation, and cell viability exceeded $90 \%$, as tested by erythrosin exclusion (Krause et al, 1984). HSC were grown on uncoated plastic in $75 \mathrm{~cm}^{2}$ flasks until confluency, in DMEM containing 20\% serum (10\% fetal calf/10\% horse), $4 \mathrm{~mm}$ L-glutamine, and 100,000 IU-100 mg/l penicillin-streptomycin. Medium was changed 24 hours after plating, and every 48 hours thereafter.

\section{Hepatocyte Isolation}

Hepatocytes were isolated from normal rats by a method derived from Seglen (1976). The liver was perfused in situ, for 15 minutes with a $\mathrm{Ca}^{2+}$-free 10 mм Hepes buffer at a flow rate of $30 \mathrm{ml} /$ minute, and for 15 minutes with $0.025 \%$ collagenase $\mathrm{B}$ in $\mathrm{Ca}^{2+}$. containing $10 \mathrm{~mm}$ Hepes buffer at a flow rate of 20 $\mathrm{ml} / \mathrm{minute}$. The hepatocytes were then separated from the connective tissue by gentle agitation in L15 containing $0.2 \%$ BSA. The resulting cell suspension was filtered through gauze, allowed to sediment for 20 minutes at $4^{\circ} \mathrm{C}$, and washed in BSA-containing L15. Hepatocytes were $80 \%$ to $85 \%$ pure, as assessed by characteristic cell size under phase-contrast microscopy, and cell viability exceeded $90 \%$.

\section{Cell Migration Assay}

Cell migration was assessed by a Transwell chemotaxis filter assay (Becton Dickinson). Cell culture inserts equipped with a $8-\mu \mathrm{m}$-pore membrane of 0.3 $\mathrm{cm}^{2}$ were placed in 24-well culture dishes, forming the upper and lower compartments of the assay, respec- 
tively. The bottom wells and membranes were precoated with type I collagen $(50 \mathrm{mg} / \mathrm{l})$. The bottom wells contained medium alone (DMEM/0.2\% BSA) as a control, PDGF-BB (10 to $100 \mu \mathrm{g} / \mathrm{l}), \mathrm{ET}-1\left(10^{-8} \mathrm{M}\right)$, or isolated bile duct segments prepared as follows. Immediately after isolation from normal or bile ductligated rats, bile duct segments were plated at a density of $1.5 \times 10^{3}$ segments/ml in DMEM/Ham's F12, supplemented with $2 \%$ Ultroser G, $4.85 \mathrm{~g} / \mathrm{l}$ D-glucose, $2.5 \mathrm{~mm}$ l-glutamine, 100,000 IU-100 mg/l penicillin-streptomycin and $2 \mathrm{mg} / \mathrm{l}$ fungizone. The segments were allowed to adhere for 12 hours, and then washed 3 times and placed in serum-free DMEM/ $0.2 \%$ BSA for 24 hours before the assay. In inhibition experiments, neutralizing anti-PDGF polyclonal IgG (50 mg/l; Becton-Dickinson), control non-selective isotype-matched IgG (50 mg/l; Becton-Dickinson), STI571 $\left(10^{-5} \mathrm{M}\right)$, or Bosentan $\left(10^{-5} \mathrm{M}\right)$, were added to the bottom wells. The top wells of the chemotaxis filter assay were seeded with HSC, according to the following procedure. Confluent HSC between 1 and 4 passages in culture, were serum-starved by incubation in serum-free DMEM/0.2\% BSA for 48 hours, and then detached by mild trypsinization in $0.05 \%$ trypsin/ $0.2 \%$ EDTA for 1 to 2 minutes. The reaction was stopped by adding an equal volume of $5 \mathrm{~g} / \mathrm{l}$ trypsin inhibitor solution. HSC were washed and resuspended in DMEM/ $0.2 \%$ BSA, at a density of $3.5 \times 10^{5} \mathrm{cells} / \mathrm{ml}$. Two hundred microliters of the cell suspension were added to the top wells and incubated for 6 hours. All incubations were carried out under air $/ \mathrm{CO}_{2} 95 \% / 5 \%$, at $37^{\circ} \mathrm{C}$. At the end of experiments, the cells remaining on the upper surface of filters were removed with cotton tips. The membranes were fixed in $100 \%$ methanol, stained with May-Grünwald-Giemsa, mounted in Glycergel on glass slides, and examined under an Olympus $\mathrm{BH}-2$ microscope. Cells adhering to the underside of membranes were counted in 10 random high-power fields $(\times 400)$, and the mean count was determined from duplicate experiments. To verify that, in bottom wells, the number of bile duct segments did not differ between preparations from normal and bile duct-ligated rats, DNA content was determined, following extraction with QIAamp Blood Kit, by spectrophotometry.

\section{Reverse Transcription-Polymerase Chain Reaction}

Total RNA was extracted from freshly isolated hepatocytes, bile duct segments and culture activated HSC, using Qiagen RNA/DNA kit. One microgram of total RNA was denatured by heating at $65^{\circ} \mathrm{C}$ for 10 minutes and then incubated in $20 \mu \mathrm{l}$ of a reaction buffer (50 mM Tris-HCL [pH 8.3], $3 \mathrm{~mm} \mathrm{MgCl}_{2}$ and 75 $\mathrm{mm} \mathrm{KCl)} \mathrm{containing} 10 \mathrm{~mm} 1,4-\mathrm{DTT}, 0.5 \mathrm{~mm}$ of deoxynucleoside triphosphate mixture, $5 \mu \mathrm{M}$ random hexamers, and $1 \mu \mathrm{l}$ of Superscript reverse transcriptase. Reverse transcription was allowed to proceed for 45 minutes at $42^{\circ} \mathrm{C}$, and was stopped by incubation at $68^{\circ} \mathrm{C}$ for 10 minutes. The samples were then transferred on ice before the PCR run. Based on the published sequence of rat PDGF-B cDNA (Herren et al, 1993), the following primers were selected: 5'GTA GAC GAA GAT GGG GCT GA 3' (sense) and 5'TCT GTA CGC GTC TTG CAC TC 3' (antisense), that generate a $149 \mathrm{bp}$ product of PDGF-B chain cDNA. Primers of G3PDH cDNA used as internal standard were designed to amplify a cDNA fragment of $195 \mathrm{bp}$ (Narayanan et al, 1992). Amplification of cDNA fragments was accomplished using a thermocycler (Perkin-Elmer Cetus, Norwalk, Connecticut) by adding $3 \mu \mathrm{l}$ of cDNA to a final volume of $50 \mu \mathrm{l} \mathrm{PCR}$ buffer (20 $\mathrm{mm}$ Tris- $\mathrm{HCl}[\mathrm{pH} 8.4]$ and $50 \mathrm{~mm} \mathrm{KCl}$ ) containing 1.5 $\mathrm{mm} \mathrm{MgCl}_{2}, 0.2 \mathrm{~mm}$ of deoxynucleoside triphosphate mixture, and $0.025 \mathrm{U} / \mu$ l of Taq DNA polymerase. The reaction was carried out in the presence of $0.2 \mu \mathrm{M}$ of PDGF-B and G3PDH primers, respectively. The thermal conditions of amplification were those of stepdown PCR (Hecker and Roux, 1996). After an initial 5 -minute denaturation at $94^{\circ} \mathrm{C}$, the cycling program consisted of (a) 1-minute denaturation at $94^{\circ} \mathrm{C}$, (b) 1-minute annealing, initially at $60^{\circ} \mathrm{C}$, followed by a decrease of $1^{\circ} \mathrm{C}$ every six cycles, (c) extension at $72^{\circ} \mathrm{C}$, for 1 minute, and 3 minutes in the end. During $\mathrm{PCR}$, samples were withdrawn at regular intervals between 24 and 36 cycles. PCR products were separated on $2 \%$ agarose gels stained with ethidium bromide, and quantified by scanning densitometry (Arcus II; AGFA, Rueil Malmaison, France).

\section{Cytochemistry and Immunocytochemistry}

Bile duct segments and HSC were prepared as follows for (immuno)cytochemical analyses. Immediately after isolation, bile duct segments were washed in phosphate-buffered saline, centrifuged onto glass slides in a Cytospin (Shandon Inc., Pittsburgh, Pennsylvania) at $600 \mathrm{rpm}$ for 10 minutes, and fixed in $100 \%$ acetone at $4^{\circ} \mathrm{C}$ for 10 minutes. Culture activated HSC were either grown on LabTek slides (Miles laboratories Naperville, Illinois), washed in TRIS buffer solution, $\mathrm{pH}$ 7.6, and fixed in $100 \%$ methanol at $4^{\circ} \mathrm{C}$ for 10 minutes, or detached in $0.05 \%$ trypsin/0.2\% EDTA, allowed to adhere to positively charged glass slides (SuperFrost/plus; Fisher Scientifique, Elancourt, France) for 20 minutes, and fixed in $4 \%$ paraformaldehyde for 15 minutes. $\gamma$-Glutamyl transpeptidase activity was revealed as described (Rutenberg et al, 1968), by incubations in $\gamma$-Glutamyl-4-methoxy-2naphthylamide, Glycylglycine, and fast blue BB for 15 minutes, and then in $0.1 \mathrm{~m}$ cupric sulfate for 2 minutes. Indirect immunocytochemical procedures were applied to cell preparations, using anti-cytokeratin 19 (1:10), anti- $\alpha$-SMA (1:100), anti-PDGFR- $\beta$ (5 mg/l), or anti-PDGF-BB (5 mg/l) antibodies, as primary antibodies. In alkaline phosphatase anti-alkaline phosphatase method, the slides were successively incubated with primary monoclonal antibodies for 30 minutes at room temperature, with rabbit anti-mouse polyclonal antibodies for 30 minutes, and with the alkaline phosphatase anti-alkaline phosphatase immune complex. Color reaction was developed by incubation with Fast red for 25 minutes. In three-step immunoperoxidase method, the slides were successively incubated with 
primary monoclonal antibodies, with peroxidaseconjugated rabbit anti-mouse and anti-rabbit polyclonal antibodies. In biotin-avidin-peroxidase method, endogenous biotin activity and goat IgG Fc interactions were quenched by using SP-2001 avidin-biotin blocking kit, and by a 20 -minute incubation with $1 \%$ normal goat serum, respectively. The slides were then successively incubated with primary monoclonal antibodies for 12 hours, with goat biotinylated anti-rabbit IgG (1:400) for 30 minutes, and with an avidin-biotinperoxidase complex, using Vectastain ABC-HP-kit, for 30 minutes, at room temperature. Peroxidase activity was revealed by the chromogen substrates 3-amino9-ethylcarbazole or diaminobenzidine. The slides were counterstained with Mayer's hematoxylin and mounted in Glycergel aqueous medium. In negative controls, the primary antibodies were omitted or replaced by irrelevant isotype-matched antibodies.

\section{Statistics}

Results were analyzed using one-way analysis of variance (ANOVA) and Tukey's multiple comparison test for comparison between multiple groups, and Student's paired $t$ test for comparison of paired samples. Statistics were performed after logarithmic transformation when appropriate. $p<0.05$ was considered significant.

\section{Acknowledgements}

The authors are indebted to Dr. Elisabeth Buchdunger, Novartis Pharma Inc., Basel, Switzerland, for the gift of STI571, to Dr. Martine Clozel, Actelion Ltd., Allschwil, Switzerland, for providing Bosentan, and to Dr. Jean Rosenbaum, Université V. Segalen, Bordeaux, France, for the kind gift of PDGF-B primers.

\section{References}

Abdel-Aziz G, Rescan P-Y, Clément B, Lebeau G, Rissel M, Grimaud J-A, Campion J-P, and Guillouzo A (1991). Cellular sources of matrix proteins in experimentally induced cholestatic rat liver. J Pathol 164:167-174.

Buchdunger E, Zimmermann J, Mett H, Meyer T, Muller M, Druker BJ, and Lydon NB (1996). Inhibition of the Abl protein-tyrosine kinase in vitro and in vivo by a 2-phenylaminopyrimidine derivative. Cancer Res 56:100104.

Carloni V, Romanelli RG, Pinzani M, Laffi G, and Gentilini P (1997). Focal adhesion kinase and phospholipase $C \gamma$ involvement in adhesion and migration of human hepatic stellate cells. Gastroenterology 112:522-531.

Clozel M, Breu V, Gray GA, Kalina B, Löffler B-M, Burri K, Cassal J-M, Hirth G, Müller M, Neidhart W, and Ramuz H (1994). Pharmacological characterization of bosentan, a new potent orally active nonpeptide receptor antagonist. J Pharmacol Exp Ther 270:228-235.

Desmet V, Roskams T, and Van Eyken P (1995). Ductular reaction in the liver. Pathol Res Pract 191:513-524.

Friedman SL (1993). The cellular basis of hepatic fibrosis. N Engl J Med 328:1828-1835.
Friedman SL, and Arthur MJP (1989). Activation of rat hepatic lipocytes by Kupffer cell conditioned medium. Direct enhancement of matrix synthesis and stimulation of proliferation via induction of platelet-derived growth factor receptors. J Clin Invest 84:1780-1785.

Friedman S, and Roll F (1987). Isolation and culture of hepatic lipocytes, Kupffer cells, and sinusoidal endothelial cells by density gradient centrifugation and stractan. Anal Biochem 161:207-218.

Grappone C, Pinzani M, Parola M, Pellegrini G, Caligiuri A, DeFranco R, Marra F, Herbst H, Alpini G, and Milani S (1999). Expression of platelet-derived growth factor in newly formed cholangiocytes during experimental biliary fibrosis in rats. J Hepatol 31:100-109.

Grinko I, Geerts A, and Wisse E (1995). Experimental biliary fibrosis correlates with increased numbers of fat-storing and Kupffer cells, and portal endotoxemia. J Hepatol 23:449458.

Hardonk MJ, and Atmosoerodjo-Briggs J (1992). Evidence for the anatomical connection between the space of Disse and the portal tract in human and rat liver. In: Knook DL and Wisse E, editors. Cells of the hepatic sinusoid: Proceedings of the Sixth International Kupffer Cell Symposium. Antwerp: The Kupffer Cell Foundation, 182-184.

Hart CE, Forstrom JW, Kelly JD, Seifert RA, Smith RA, Ross R, Murray MJ, and Bowen-Pope DF (1988). Two classes of PDGF receptor recognize different isoforms of PDGF. Science 240:1529-1531.

Hecker KH, and Roux KH (1996). High and low annealing temperatures increase both specificity and yield in touchdown and stepdown PCR. Biotechniques 20:478-485.

Heldin CH, Backstrom G, Ostman A, Hammacher A, Ronnstrand L, Rubin K, Nister M, and Westermark B (1988). Binding of different dimeric forms of PDGF to human fibroblasts: Evidence for two separate receptor types. Embo J 7:1387-1393.

Herren B, Weyer KA, Rouge M, Lotscher P, and Pech M (1993). Conservation in sequence and affinity of human and rodent PDGF ligands and receptors. Biochim Biophys Acta 1173:294-302.

Hines JE, Johnson SJ, and Burt AD (1993). In vivo responses of macrophages and perisinusoidal cells to cholestatic liver injury. Am J Pathol 142:511-518.

Housset C, Carayon A, Housset B, Legendre C, Hannoun L, and Poupon R (1993a). Endothelin-1 secretion by human gallbladder epithelial cells in primary culture. Lab Invest 69:750-755.

Housset C, Rockey DC, and Bissell DM (1993b). Endothelin receptors in rat liver: Lipocytes as a contractile target for endothelin-1. Proc Natl Acad Sci USA 90:9266-9270.

Hultcrantz R, Mengarelli S, and Strandvik B (1986). Morphological findings in the liver of children with cystic fibrosis: A light and electron microscopical study. Hepatology 6:881889.

Ikeda K, Wakahara T, Wang YQ, Kadoya H, Kawada N, and Kaneda K (1999). In vitro migratory potential of rat quiescent hepatic stellate cells and its augmentation by cell activation. Hepatology 29:1760-1767.

Kountouras J, Billing BH, and Scheuer PJ (1984). Prolonged bile duct obstruction: A new experimental model for cirrhosis in the rat. Br J Exp Pathol 65:305-311. 
Krause AW, Carley WW, and Webb WW (1984). Fluorescent erythrosin $B$ is preferable to tryptan blue as a vital exclusion dye for mammalian cells in monolayer culture. J Histochem Cytochem 32:1084-1090.

Lindblad A, Hultcrantz R, and Strandvik B (1992). Bile-duct destruction and collagen deposition: A prominent ultrastructural feature of the liver in cystic fibrosis. Hepatology 16:372381.

Maher J, and McGuire R (1990). Extracellular matrix gene expression increases preferentially in rat lipocytes and sinusoidal endothelial cells during hepatic fibrosis in vivo. $\mathrm{J}$ Clin Invest 86:1641-1648.

Malizia G, Brunt EM, Peters MG, Rizzo A, Broekelmann TJ, and McDonald JA (1995). Growth factor and procollagen type I gene expression in human liver disease. Gastroenterology 108:145-156.

Mallat A, Fouassier L, Préaux AM, Serradeil-Le Gal C, Raufaste D, Rosenbaum J, Dhumeaux D, Jouneaux C, Mavier P, and Lotersztajn S (1995). Growth inhibitory properties of endothelin-1 in human hepatic myofibroblastic Ito cells. $\mathrm{J}$ Clin Invest 96:42-49.

Marra F, Gentilini A, Pinzani M, Choudhury GG, Parola M, Herbst H, Dianzani MU, Laffi G, Abboud HE, and Gentilini $P$ (1997). Phosphatidylinositol 3-kinase is required for plateletderived growth factor's actions on hepatic stellate cells. Gastroenterology 112:1297-1306.

Marra F, Romanelli RG, Giannini C, Failli P, Pastacaldi S, Arrighi MC, Pinzani M, Laffi G, Montalto $P$, and Gentilini $P$ (1999). Monocyte chemotactic protein-1 as a chemoattractant for human hepatic stellate cells. Hepatology 29:140148.

Mennone A, Alvaro D, Cho W, and Boyer JL (1995). Isolation of small polarized bile duct units. Proc Natl Acad Sci USA 92:6527-6531.

Narayanan R, Lawlor KG, Schaapveld RQJ, Cho KR, Vogelstein B, Tran PB-V, Osborne MP, and Telang NT (1992). Antisense RNA to the putative tumor-suppressor gene DCC transforms Rat-1 fibroblasts. Oncogene 7:553-561.

Peacock AJ, Dawes KE, Shock A, Gray AJ, Reeves JT, and Laurent GJ (1992). Endothelin-1 and endothelin-3 induce chemotaxis and replication of pulmonary fibroblasts. Am J Respir Cell Mol Biol 7:492-499.

Pinzani M, Gesualdo L, Sabbah GM, and Abboud HE (1989). Effects of platelet-derived growth factor and other polypeptide mitogens on DNA synthesis and growth of cultured rat liver fat-storing cells. J Clin Invest 84:1786-1793.

Pinzani M, Milani S, De Franco R, Grappone C, Caligiuri A, Gentilini A, Tosti-Guerra C, Maggi M, Failli P, Ruocco C, and Gentilini P (1996a). Endothelin 1 is overexpressed in human cirrhotic liver and exerts multiple effects on activated hepatic stellate cells. Gastroenterology 110:534-548.
Pinzani M, Milani S, Herbst H, DeFranco R, Grappone C Gentilini A, Caligiuri A, Pellegrini G, Vinh Ngo D, Romanelli RG, and Gentilini P (1996b). Expression of Platelet-Derived Growth Factor and its receptors in normal human liver and during active hepatic fibrogenesis. Am J Pathol 148:785800.

Poo J-L, Jiménez W, Munoz RM, Bosch-Marcé M, Bordas N, Morales-Ruiz M, Pérez M, Deulofeu R, Solé M, Arroyo V, and Rodés J (1999). Chronic blockade of endothelin receptors in cirrhotic rats: Hepatic and hemodynamic effects. Gastroenterology 116:161-167.

Rockey DC, and Chung JJ (1996). Endothelin antagonism in experimental hepatic fibrosis. Implications for endothelin in the pathogenesis of wound healing. J Clin Invest 98:13811388.

Rockey DC, Fouassier L, Chung JJ, Carayon A, Vallée P, Rey C, and Housset C (1998). Cellular localization of endothelin-1 and increased production in liver injury in the rat: Potential for autocrine and paracrine effects on stellate cells. Hepatology 27:472-480.

Rutenberg AM, Hwakyo K, Fischbein JW, Hanker JS, Wasserkrug HL, and Seligman AM (1968). Histochemical and ultrastructural demonstration of $\gamma$-glutamyl transpeptidase activity. J Histochem Cytochem 17:517-526.

Seglen PO (1976). Preparation of isolated rat liver cells. Methods Cell Biol 13:29-83.

Tang L, Tanaka Y, Marumo F, and Sato C (1994). Phenotypic change in portal fibroblasts in biliary fibrosis. Liver 14:76-82.

Tuchweber B, Desmoulière A, Bochaton-Piallat M-L, RubbiaBrandt L, and Gabbiani G (1996). Proliferation and phenotypic modulation of portal fibroblasts in the early stages of cholestatic fibrosis in the rat. Lab Invest 74:265-278.

Vassbotn FS, Östman A, Siegbahn A, Holmsen H, and Heldin C-H (1992). Neomycin is a platelet-derived growth factor (PDGF) antagonist that allows discrimination of PDGF $\alpha$ - and $\beta$-receptor signals in cells expressing both receptor types. J Biol Chem 267:15635-15641.

Wong L, Yamasaki G, Johnson RJ, and Friedman SL (1994). Induction of $\beta$-platelet-derived growth factor receptor in rat hepatic lipocytes during cellular activation in vivo and in culture. J Clin Invest 94:1563-1569. 